University of Nebraska - Lincoln

DigitalCommons@University of Nebraska - Lincoln

7-2007

\title{
Evaluation of an Experimental LiDAR for Surveying a Shallow, Braided, Sand-Bedded River
}

\author{
Paul J. Kinzel \\ United States Geological Survey, Geomorphology and Sediment Transport Laboratory, 4620 Technology \\ Drive, Suite 400, Golden, $C 0$ \\ C. Wayne Wright \\ Physical Scientist, National Aeronautics and Space Administration, Laboratory for Hydrospheric \\ Processes, Code 614.6, Goddard Space Flight Center, Wallops Island, VA \\ Jonathan M. Nelson \\ United States Geological Survey \\ Aaron R. Burman \\ United States Geological Survey
}

Follow this and additional works at: https://digitalcommons.unl.edu/usgsstaffpub

Part of the Earth Sciences Commons

Kinzel, Paul J.; Wright, C. Wayne; Nelson, Jonathan M.; and Burman, Aaron R., "Evaluation of an Experimental LiDAR for Surveying a Shallow, Braided, Sand-Bedded River" (2007). USGS Staff -- Published Research. 77.

https://digitalcommons.unl.edu/usgsstaffpub/77

This Article is brought to you for free and open access by the US Geological Survey at DigitalCommons@University of Nebraska - Lincoln. It has been accepted for inclusion in USGS Staff -- Published Research by an authorized administrator of DigitalCommons@University of Nebraska - Lincoln. 


\title{
Evaluation of an Experimental LiDAR for Surveying a Shallow, Braided, Sand-Bedded River
}

\author{
Paul J. Kinzel' ${ }^{1}$; C. Wayne Wright ${ }^{2}$; Jonathan M. Nelson ${ }^{3}$; and Aaron R. Burman ${ }^{4}$
}

\begin{abstract}
Reaches of a shallow $(<1.0 \mathrm{~m})$, braided, sand-bedded river were surveyed in 2002 and 2005 with the National Aeronautics and Space Administration's Experimental Advanced Airborne Research LiDAR (EAARL) and concurrently with conventional surveygrade, real-time kinematic, global positioning system technology. The laser pulses transmitted by the EAARL instrument and the return backscatter waveforms from exposed sand and submerged sand targets in the river were completely digitized and stored for postflight processing. The vertical mapping accuracy of the EAARL was evaluated by comparing the ellipsoidal heights computed from ranging measurements made using an EAARL terrestrial algorithm to nearby $(<0.5 \mathrm{~m}$ apart) ground-truth ellipsoidal heights. After correcting for apparent systematic bias in the surveys, the root mean square error of these heights with the terrestrial algorithm in the 2002 survey was $0.11 \mathrm{~m}$ for the 26 measurements taken on exposed sand and $0.18 \mathrm{~m}$ for the 59 measurements taken on submerged sand. In the 2005 survey, the root mean square error was $0.18 \mathrm{~m}$ for 92 measurements taken on exposed sand and $0.24 \mathrm{~m}$ for 434 measurements on submerged sand. In submerged areas the waveforms were complicated by reflections from the surface, water column entrained turbidity, and potentially the riverbed. When applied to these waveforms, especially in depths greater than $0.4 \mathrm{~m}$, the terrestrial algorithm calculated the range above the riverbed. A bathymetric algorithm has been developed to approximate the position of the riverbed in these convolved waveforms and preliminary results are encouraging.
\end{abstract}

DOI: 10.1061/(ASCE)0733-9429(2007)133:7(838)

CE Database subject headings: Bathymetry; Remote sensing; River beds; Riverine bars; Shallow water; Sand.

\section{Introduction}

Recently, there has been increasing interest by scientists in the application of remote-sensing technologies for the purpose of collecting bathymetric and topographic data in and along shallow river channels. The common goal of this research has been the development of techniques that can provide greater efficiency and increased levels of spatial detail and temporal resolution than could otherwise be gathered through conventional land-based topographic and bathymetric surveys of rivers. These remotely sensed methods have been used to identify patterns of fluvial erosion and deposition (Lane et al. 2003), provided data for riparian and in-channel habitat mapping (Marcus et al. 2003)

\footnotetext{
${ }^{1}$ Hydrologist, United States Geological Survey, Geomorphology and Sediment Transport Laboratory, 4620 Technology Drive, Suite 400, Golden, CO 80403. E-mail: pjkinzel@usgs.gov

${ }^{2}$ Physical Scientist, National Aeronautics and Space Administration, Laboratory for Hydrospheric Processes, Code 614.6, Goddard Space Flight Center, Wallops Island, VA 23337.

${ }^{3}$ Hydrologist, United States Geological Survey, Geomorphology and Sediment Transport Laboratory, 4620 Technology Drive, Suite 400, Golden, CO 80403.

${ }^{4}$ Hydrologist, United States Geological Survey, Geomorphology and Sediment Transport Laboratory, 4620 Technology Drive, Suite 400, Golden, CO 80403.

Note. Discussion open until December 1, 2007. Separate discussions must be submitted for individual papers. To extend the closing date by one month, a written request must be filed with the ASCE Managing Editor. The manuscript for this technical note was submitted for review and possible publication on August 31, 2005; approved on October 3, 2006. This technical note is part of the Journal of Hydraulic Engineering, Vol. 133, No. 7, July 1, 2007. CASCE, ISSN 0733-9429/2007/7$838-842 / \$ 25.00$.
}

and for hydraulic-modeling studies (Marks and Bates 2000).

Up to this point these methods could be placed into two categories. Those studies that have made use of a passive aerial sensor (some form of aerial imagery) only, and those that have used an active aerial sensor (commonly a laser) combined with a passive sensor. Techniques using passive sensors employ imagery and field calibration to determine a relationship between the spectral reflectance of a riverbed as a function of the overlying water depth. These relationships are spatially propagated through the imagery to generate maps of water depth. This passive sensor only approach has been demonstrated with aerial black and white imagery (Gilivear et al. 1995), multispectral imagery (Winterbottom and Gilivear 1997) and multispectral and hyperspectral imagery (Legleiter et al. 2004).

These techniques have been generally applied in gravelbedded rivers where the influence of turbidity on riverbed spectral reflectance is less of a concern than it would be in sand-bedded rivers. Other requirements to address include the need for field calibration data sets, having to plan the collection of imagery to minimize the effect of sun-angle and cloud cover and accounting for variability in bottom reflections caused by heterogeneous substrates. Another consideration in using the above-mentioned image analysis techniques is that they only provide data in wetted areas (depths). For many applications a complete elevation map of the river including exposed areas and floodplain is desired. This may require an additional technique, such as photogrammetry, to be used above the waterline and the conversion of depths to elevations which necessitate surveys of the water-surface profile as demonstrated by Westway et al. (2003).

Over the last few decades the technology and application of airborne laser altimetry or light detection and ranging systems (LiDAR) for mapping topography has undergone a rapid evolu- 
tion as these systems have transitioned from being research tools to operational systems widely available from commercial vendors. Studies which have made use of LiDAR-collected topographic data along rivers and floodplains include: Marks and Bates (2000); Bowen and Waltermire (2002), and Charlton et al. (2003). Due to the attenuation of these infrared LiDARs in water, the topographic portion of a LiDAR data set has been combined with passive techniques applied in the wetted areas to create complete maps of river topography and bathymetry (Hicks et al. 2001; Lane et al. 2003).

The use of airborne lasers to measure bathymetry, however, is considerably more complex and challenging than topographic mapping for a variety of technical and environmental reasons. The attenuation of the laser beam within the water column is much greater than an equivalent length of air. Additionally specular reflections of the laser from the water surface cover a very large range of return signal amplitudes. Strong specular reflections can effectively overload the LiDAR receiver and blind it to weak backscatter signals coming from a shallow bottom a few billionths of a second afterward. In contrast, many backscattered signals have no apparent surface reflection component and are dominated by much weaker water column backscatter thus making it difficult to determine where the actual surface of the water is located. Highly specialized electrooptical electronic circuits and schemes are typically employed to mitigate these conditions in bathymetric LiDARs. These schemes usually significantly trade-off shallow water performance in favor of deeper water signal detection. As such, bathymetric LiDARs remain a highly specialized technology with only a handful of these instruments currently in existence and with deep clear-water coastal areas being the most common region of application (Guenther et al. 2000).

The accuracy of both terrestrial and bathymetric airborne laser altimetry depends upon the simultaneous determination of the LiDAR sensor's position and orientation in space and the roundtrip timing and orientation of each laser pulse from the aircraft to the earth's surface. The first requirement involves determination of the aircraft's trajectory using differentially processed kinematic global positioning system (GPS) combined with precise measurement of the aircraft attitude (pitch, yaw, and roll) typically with an inertial measurement unit consisting of high precision orthogonal gyroscopes and accelerometers. The second requirement, roundtrip timing, is dependent on the digitizer electronics used to sample the travel time of the transmitted pulse and returned laser backscatter waveform. The various accuracy errors associated with LiDAR systems are discussed in greater detail in Huising and Gomes Pereira (1998) and Baltsavias (1999). Most LiDARs are designed to simply measure the time to the leading edges of the first, the last, and in some cases multiple pulses within the surface backscatter(s). The internal structure of the backscatter(s), where additional information may be found, is generally not recorded. Some topographic infrared LiDARs also record a single backscattered intensity value for each time measurement.

The National Aeronautics and Space Administration's Experimental Advanced Airborne Research LiDAR (NASA EAARL) was designed to supplement recent advances in topographic LiDAR with water-penetrating capabilities and a full waveform digitization concept (Wright et al. 2001). The EAARL laser transmitter is a Continuum EPO-5000 doubled yttrium aluminum garnet (YAG) laser that produces up to 5,000, short 1.3 ns duration, $70 \mu \mathrm{J}, 532 \mathrm{~nm}$ (blue/green) pulses each second. Because of the eye safety considerations associated with bathymetric blue/green lasers, unlike terrestrial lasers that operate in the near-infrared

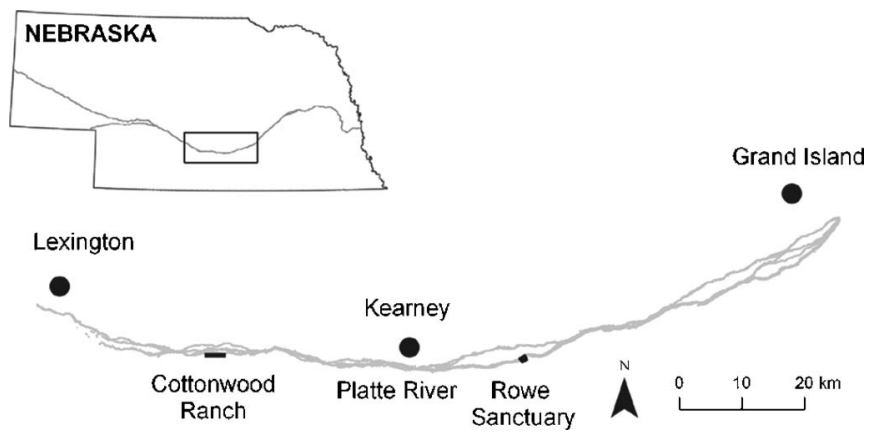

Fig. 1. The central Platte River, Neb. and locations of EAARL ground-truth comparison sites

portion of the electromagnetic spectrum, operators of highpowered bathymetric LiDARs are required to spread the laser spot intensity over a much larger area. Since the EAARL laser is only $1 / 50$ th the power of other bathymetric lasers, the spot diameter can be much smaller, $0.15 \mathrm{~m}$ as opposed to $2 \mathrm{~m}$, and still be eye safe. While this reduction in the laser power makes the EAARL laser less suitable for bathymetric measurements in water $>10 \mathrm{~m}$, the reduction in illuminated area improves the spatial resolution in shallower depths.

The EAARL is typically operated from Cessna 310 aircraft and flown at $300 \mathrm{~m}$ altitude and at $50 \mathrm{~m} / \mathrm{s}$. At this altitude and speed the laser completes 21 scans each second. The spacing of individual laser samples along each scan is $2 \times 2.5 \mathrm{~m}$ in the center and extending to $2 \times 4 \mathrm{~m}$ on the edges of the $240 \mathrm{~m}$ swath. The average along track spacing is nominally $2.5 \mathrm{~m}$.

The EAARL system utilizes special real-time adaptive waveform hardware and software to capture the most important aspects of each laser return. It automatically adapts to accommodate signal waveforms which vary widely in temporal extent and signal dynamic range. The entire structure of the transmitted and returned laser pulses are digitized and stored by the EAARL hardware. As such, the system can accommodate the extreme variations in laser backscatter complexity and signal strength caused by the diverse optical and physical characteristics associated with bare earth, submerged, and vegetated surfaces found along coastal areas (Wright and Brock 2002).

This study was undertaken to evaluate the vertical accuracy in using the EAARL to simultaneously measure river channel topography and bathymetry. The success of bathymetric LiDARs in mapping bottom topography is dependent upon the clarity of the overlying water. However, for rivers of sufficient clarity, and/or of shallow depth, bathymetric LiDARs have the potential of providing another alternative for collecting detailed topographic and bathymetric data. This note describes an evaluation of the EAARL instrument for surveying a shallow, braided, sandbedded river.

\section{Study Area}

The central Platte River in Nebraska was chosen as the location to evaluate the EAARL system in a riverine environment (Fig. 1). The Platte River was selected, in part, because it epitomizes the difficulties associated with collecting synoptic topographic and bathymetric data in wide $(>100 \mathrm{~m})$, shallow rivers using conventional techniques. Shallow rivers are defined by the writers to be those wherein the maximum depth is generally less than $1 \mathrm{~m}$ 
during average flow conditions. This depth range presents tremendous challenges for conventional data collection as it is generally too shallow for navigation by boat and thus prohibits the use of hydroacoustics. Further, even if the river is partially navigable at higher flows a large quantity of the survey area might consist of exposed bars, islands, riverbanks, and floodplains, which necessitate additional effort in the form of either GPS ground surveys, photogrammetry, or conventional LiDAR. If the river is shallow enough for wading, ground-based laser theodolites or surveygrade global positioning systems can be used. However, the writers have found this time and labor-intensive approach is best suited for the detailed mapping of river reaches less than a few kilometers in length.

The central Platte River also is currently (2006) the focus of Federal and State governments that have developed a habitat recovery plan for the endangered least tern, whooping crane, pallid sturgeon, and the threatened piping plover (Platte River Recovery and Implementation Program 2005). The Platte River channels have significantly narrowed over the last century due to vegetation encroachment resulting from a change in the regime of water and sediment inputs caused by upstream water-resource development (Williams 1978; Eschner et al. 1983). The current river morphology is believed to have negatively impacted habitat conditions for the endangered and threatened species (National Research Council 2004; U.S. Department of Interior 2006).

Two field sites were selected along the central Platte River for evaluation of the EAARL. One field site was located on the Cottonwood Ranch, an $11 \mathrm{~km}^{2}$ parcel of land owned by the Nebraska Public Power District (Fig. 1). The reach of the Platte River passing through this property is approximately $150 \mathrm{~m}$ wide. A dense riparian forest has developed on the floodplains and high islands along this channel over the last 70 years. The other site is located on the Lillian Annette Rowe Sanctuary and is managed by the National Audubon Society (Fig. 1). The river channel is relatively wide through the Rowe Sanctuary reach, approximately $250 \mathrm{~m}$. The channel width is maintained by annual in-channel vegetation clearing on sandbars.

On March 29, 2002 NASA flew two flight lines over the reach in the Cottonwood Ranch. The U.S. Geological Survey (USGS) surveyed 25 river cross sections using a survey-grade GPS base station and three GPS roving receivers. The ground-truth GPS survey was conducted in real-time kinematic (RTK) mode. This survey style allows rapid data collection, approximately 5-10 s per topographic measurement, with manufacturer reported vertical measurement precisions of $\pm 0.02 \mathrm{~m}$. The flow in the Platte River at the time of this survey was influenced by a shutdown of an upstream hydropower plant return canal for maintenance. Prior to the surveys, normal hydropower plant operation caused streamflows to peak as high as $30 \mathrm{~m}^{3} / \mathrm{s}$. After shutdown, streamflow declined to a constant $10 \mathrm{~m}^{3} / \mathrm{s}$ during the river surveys. The associated reduction in river stage exposed a large quantity of sandbars and reduced the depths in the study reach to less than $0.6 \mathrm{~m}$.

On June 15, 2005 NASA flew 24 flight lines over the Rowe Sanctuary study site (Kinzel et al. 2006). At the same time, USGS personnel collected elevation measurements with RTK-GPS by concentrating wading measurements along the wetted braids in the river channel. The total flow of the Platte River $16 \mathrm{~km}$ upstream at the USGS streamflow-gauging station at Kearney, Neb. was approximately $40 \mathrm{~m}^{3} / \mathrm{s}$. However, only a portion of the total streamflow (approximately 65\%) passes through the Rowe Sanctuary channel. This flow and field effort provided a larger sample and range of depths in the Rowe Sanctuary than were collected in the Cottonwood Ranch reach in 2002.

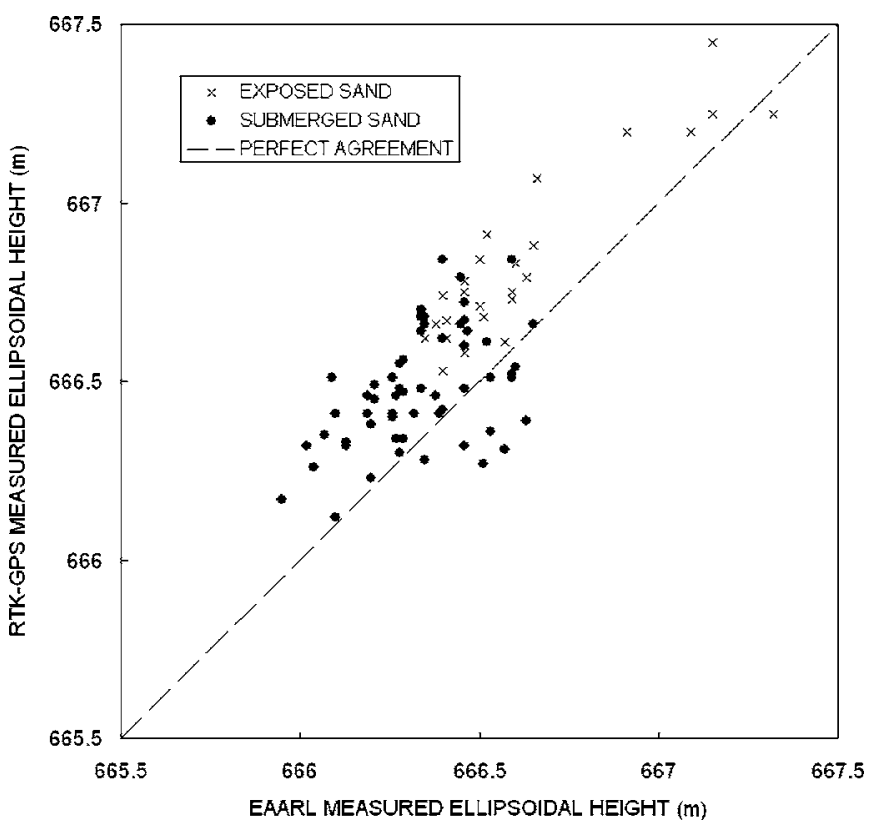

Fig. 2. Graph showing the comparison between ground-truth and unadjusted EAARL heights in the Cottonwood Ranch reach. EAARL range measurements computed with the terrestrial algorithm.

\section{Vertical Accuracy Assessment}

The ground-truth GPS point measurements were compared with the LiDAR measurements that were computed using a terrestrial algorithm that bases the ranging measurement on the interval between the time when pulse was transmitted to the time corresponding to the centroid of the return laser backscatter or waveform. Implicit in this comparison is the assumption that both data sets are in the same horizontal coordinate system. While groundbased surveys can easily detect and determine the horizontal position of linear breakline features, these features are difficult to resolve with LiDAR given that along a scanning swath topography is sampled discontinuously. Consequently, assessments of horizontal of accuracy were not made.

Geographic information system software was used to pair each ground-truth point with an adjacent LiDAR coordinate (Universal Transverse Mercator coordinate system). To assess the vertical accuracy of the LiDAR the maximum distance used to pair a LiDAR point to a ground-truth point was limited to $0.5 \mathrm{~m}$ to balance the need for minimizing the effect of local variations in topography with retaining a reasonable sample size for comparison. The datum for both surveys was the North American Datum of 1983. Although the local variation in the geoid was found to be relatively small, a geoid model was neither required nor desired to transform the ellipsoid heights to sea-level elevations. Fig. 2 shows the relationship between the ground-truth ellipsoid height and the corresponding LiDAR-derived ellipsoid height for the exposed and submerged targets in the Cottonwood Ranch. The majority of points fall above the line of perfect agreement indicating that the ground-truth heights are generally higher than the paired LiDAR height.

Other scientists that have assessed the vertical accuracy of terrestrial LiDARs (Bowen et al. 2002; Charlton et al. 2003) have found similar biases. If the bias is judged to be systematic, it is reasonable to adjust the LiDAR heights uniformly. The simplest targets, with regard to reflectivity, were the exposed sandbars in 


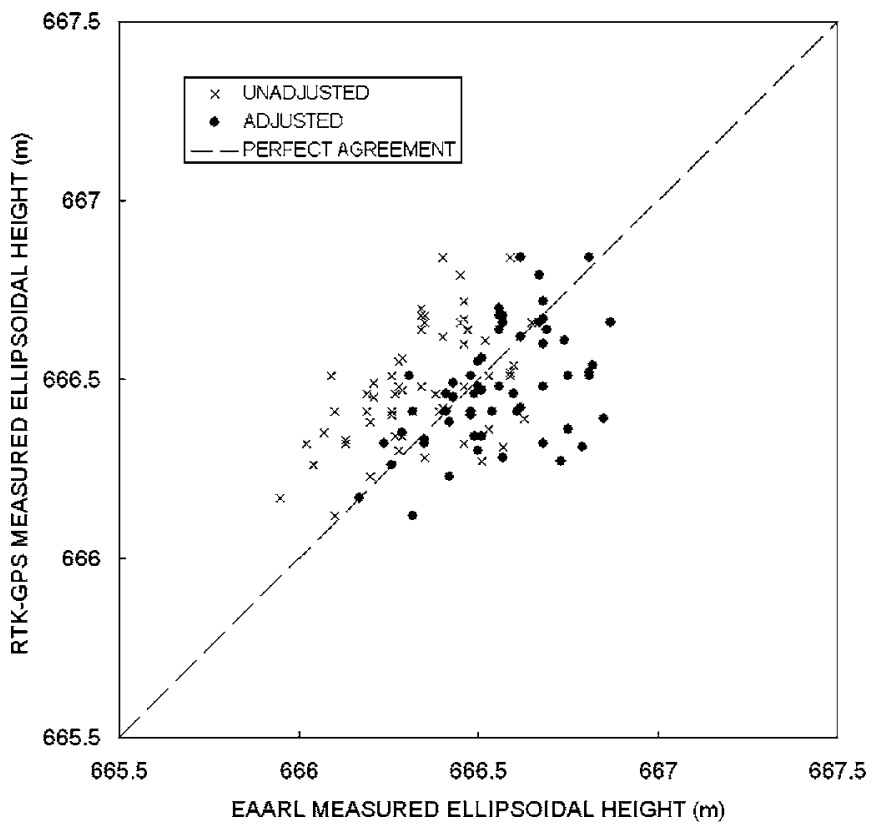

Fig. 3. Graph showing original and block adjusted submerged points in the Cottonwood Ranch reach. EAARL ranging measurements computed with the terrestrial algorithm.

the reach. The average difference or mean error between the EAARL and ground-truth heights for the exposed sand was $-0.22 \mathrm{~m}$ in the Cottonwood Ranch reach. LiDAR heights for all surface types were then adjusted by adding $0.22 \mathrm{~m}$. In 2005 the mean error between the EAARL and ground-truth heights for exposed sand in the Rowe Sanctuary reach was found to be $-0.10 \mathrm{~m}$.

\section{Discussion}

Bathymetric LiDARs are primarily used in coastal environments and the depth range considered can often be greater than $10 \mathrm{~m}$. The blue-green laser waveforms in these deep, clear waters often have at least two distinct peaks (one representing a near surface or initial volume return and the other from the bottom). Additional peaks in the waveform are commonly attributed to turbidity, marine life, or suspended particles in the water column. A separate infrared pulse is also used by some bathymetric LiDARs to aid in detecting the water surface. Bathymetric LiDAR ranging measurements are computed by accounting for the speed of light in water and measuring the time interval between the water surface (if it exists) and bottom peak.

As the EAARL blue-green laser passed through the shallow water $(<1 \mathrm{~m})$ of the Platte River, only single-peaked waveforms were observed. These bathymetric waveforms are the integrated result of the backscatter from the near surface, turbidity, and potentially from the riverbed. If the centroid of these waveforms corresponded only to the backscatter from the riverbed and were processed with the terrestrial algorithm, the ranging measurement would be longer than should be (the river would appear deeper). This is because the total travel time measured would be assumed to have occurred only through air instead of air and a small depth of water. A laser pulse travels approximately $0.15 \mathrm{~m} / \mathrm{ns}$ in air and $0.11 \mathrm{~m} / \mathrm{ns}$ in water. Thus, assuming the pulse is in air when it is actually in water results in a $4 \mathrm{~cm} / \mathrm{ns}$

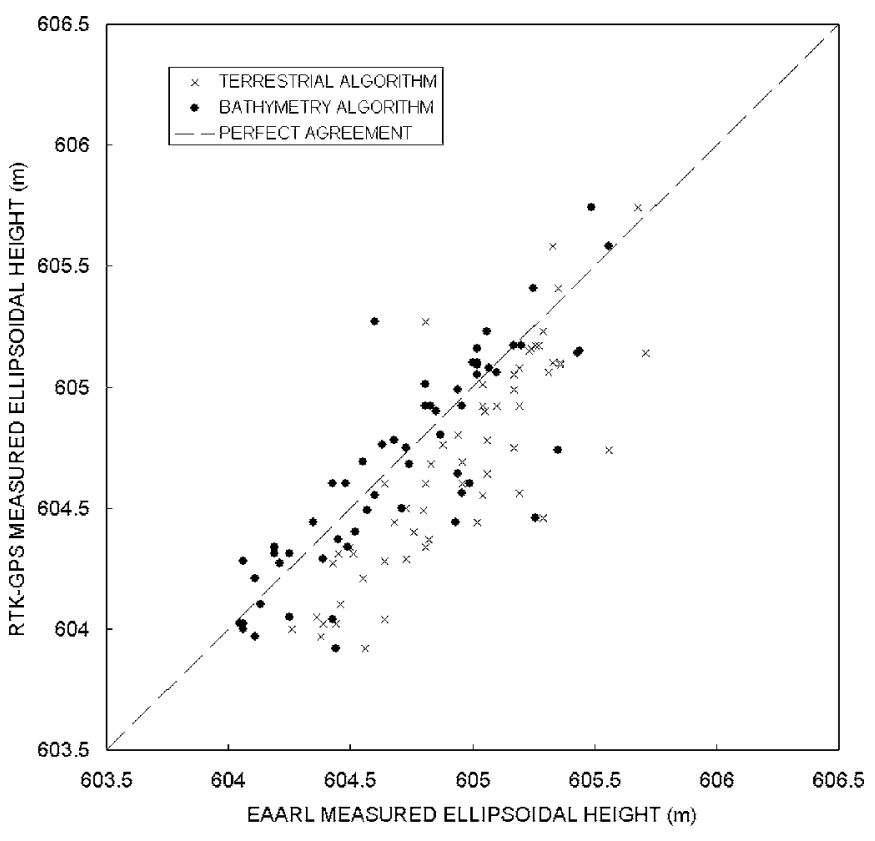

Fig. 4. Comparison of ellipsoidal heights computed with the EAARL terrestrial and bathymetric algorithms with block adjustment in the Rowe Sanctuary study site (depths $>0.4 \mathrm{~m}$ )

"deeper error" or approximately a $1.36 \mathrm{~m}$ depth measurement in $1 \mathrm{~m}$ of actual water. When the adjustment, calculated from the exposed sand, was applied to the submerged values the majority of the adjusted LiDAR heights generally fell above the groundtruth heights (Figs. 3 and 4). This result suggested the submerged backscatter did not correspond only to the riverbed but was rather a combination of backscatter from the near surface, turbidity, and potentially the riverbed. Therefore, it was not appropriate to process all submerged waveforms with the terrestrial algorithm used on exposed sand. However, this first level of processing was used to demonstrate the need for specialized algorithms to interpret these waveforms.

Closer examination of the submerged waveforms in the study sites, especially those in depths greater than $0.4 \mathrm{~m}$, revealed a number of convolved single-peaked waveforms, meaning the waveform tended to have a smaller peak magnitude than those from the exposed sand as well as a broader base due to a complex interaction of multiple backscatters. To approximate the location of the riverbed in these waveforms an algorithm was developed to separate the near surface and bottom returns. The bathymetric algorithm attempts to suppress water surface effects and water column backscatter by modeling and subtracting the exponential decay of the laser pulse and the water column portion of the backscatter. Additionally it discriminates against backscatter which does not fit acceptable pulse heights and widths for bottom return pulses. The bathymetric algorithm computes the total range accounting for the portion of laser pulse traveling through air and the portion traveling between the near surface and bottom. Fig. 4 shows the adjusted terrestrial algorithm compared with the adjusted bathymetric algorithm compared to the same groundtruth points that were collected in water deeper than $0.4 \mathrm{~m}$ in the Rowe Sanctuary reach. The bathymetric algorithm shifted the EAARL ellipsoid heights toward the line of perfect agreement and reduced the mean error from 0.26 to $0.04 \mathrm{~m}$ and the rootmean-square error of these heights (RMSEh) from 0.35 to $0.24 \mathrm{~m}$ $(n=58)$. 


\section{Conclusions}

The vertical mapping accuracy (RMSEh) of the EAARL LiDAR using a terrestrial algorithm and including a bias adjustment was determined to be $0.11 \mathrm{~m}$ for exposed sand targets and $0.18 \mathrm{~m}$ for all submerged targets in the Cottonwood Ranch reach and 0.18 and $0.24 \mathrm{~m}$ in the Rowe Sanctuary reach. The terrestrial algorithm, when applied to submerged targets, would measure the elevation of submerged targets lower than the actual elevation, assuming the backscatter is made up of only a riverbed reflection. In the Cottonwood Ranch and the Rowe Sanctuary surveys this was generally not observed. The bathymetric waveforms were the result of a combination of near surface, turbidity and potentially riverbed backscatter. A shallow-water bathymetric algorithm was developed and shown to improve both the mean error and root mean square error of the elevation of the riverbed in depths greater than $0.4 \mathrm{~m}$. Continued collaboration with NASA is planned to aid in the testing of processing algorithms for shallow bathymetric waveforms. Future plans call for the integration of a hyperspectral scanner to the EAARL instrument package which would provide the means to compare bathymetric LiDAR measurements with passive techniques in a sand-bed channel.

\section{Acknowledgments}

The writers would like to thank the National Audubon Society and the Nebraska Public Power District for allowing access to reaches of the Platte River located on their properties. Assistance with the EAARL postflight processing software ALPS (Airborne Laser Processing Software) was kindly provided by Amar Nayegandhi (U.S. Geological Survey) and Richard Mitchell (National Aeronautics and Space Administration). This research was supported by the U.S. Geological Survey's Venture Capital Fund. The use of trade, firm, or product names is for descriptive purposes only and does not imply endorsement by the U.S. Government.

\section{References}

Baltsavias, E. P. (1999). "Airborne laser scanning: Basic relations and formulas." ISPRS J. Photogramm. Remote Sens., 54, 199-214.

Bowen, Z. H., and Waltermire, R. G. (2002). "Evaluation of light distancing and ranging (LiDAR) for measuring river corridor topography." J. Am. Water Resour. Assoc., 38(1), 33-41.

Charlton, M. E., Large, A. R. G., and Fuller, I. C. (2003). "Application of airborne LIDAR in river environments: The River Coquet, Northumberland, UK." Earth Surf. Processes Landforms, 28(3), 299-306.

Eschner, T. R., Hadley, R. F., and Crowley, K. D. (1983). "Hydrologic and morphologic changes in channels of the Platte River basin in Colorado, Wyoming and Nebraska-A historical perspective." U.S. Geological Survey Professional Paper No. 1277-A, Washington, D.C.

Gilvear, D. J., Walters, T., and Milner, A. (1995). "Image analysis of aerial photography to quantify changes in channel morphology and instream habitat following placer mining in interior Alaska." Freshwater Biol., 34, 389-398.
Guenther, G. C., Cunningham, A. G., LaRocque, P. E., and Reid, D. J. (2000). "Meeting the accuracy challenge in airborne LIDAR bathymetry." Proc., 20th EARSeL Symp.: Workshop on Lidar Remote Sensing of Land and Sea, European Association of Remote Sensing Laboratories, Dresden, Germany.

Hicks, D. M., Duncan, M. J., Walsh, J. M., Westaway, R. M., and Lane, S. N. (2001). "New views of the morphodynamics of large braided rivers from high-resolution topographic surveys and time-lapse video." The structure, function, and management implications of fluvial sedimentary systems, F. J. Dyer, M. C. Thoms, and J. M. Olley, eds., IAHS Publication No. 276, 373-380.

Huising, E. J., and Gomes Pereira, L. M. (1998). "Errors and accuracy estimates of laser data acquired by various laser scanning systems for topographic applications." ISPRS J. Photogramm. Remote Sens., 53, 245-261.

Kinzel, P. J., Wright, C. W., and Nelson, J. M. (2006). "Application of an experimental airborne laser scanner for surveying a braided river channel." Proc., 8th Federal Interagency Sedimentation Conf., Federal Interagency Sedimentation Program, Reno, Nev.

Lane, S. A., Westway, R. M., and Hicks, D. M. (2003). "Estimation of erosion and deposition volumes in a large, gravel-bed, braided river using synoptic remote sensing." Earth Surf. Processes Landforms, 28(3), 249-271.

Legleiter, C. J., Roberts, D. A., Marccus, W. A., and Fonstad, M. A. (2004). "Passive optical remote sensing of river channel morphology and in-stream habitat: Physical basis and feasibility." Remote Sens. Environ., 93, 493-510.

Marcus, W. A., Legleiter, C. J., Aspinall, R. J., Boardman, J. W., and Crabtree, R. L. (2003). "High spatial resolution hyperspectral mapping of in-stream habitats, depths, and woody debris in mountain streams." Geomorphology, 55, 363-380.

Marks, K., and Bates, P. (2000). "Integration of high-resolution topographic data with floodplain flow models." Hydrolog. Process., 14, 2109-2122.

National Research Council. (2004). Endangered and threatened species of the Platte River, National Academies Press, Washington, D.C.

Platte River Recovery Implementation Program. (2005). "Platte River Recovery Implementation Program Cooperative Agreement." 〈http://www.platteriver.org/library/Program-Document-Dec-2005/ Program.pdf $\rangle$ (June 1, 2006).

U.S. Department of the Interior. (2006). "Platte River recovery implementation program final environmental impact statement." 〈http:// www.platteriver.org (June 1, 2006).

Westway, R. M., Lane, S. N., and Hicks, D. M. (2003). "Remote survey of large-scale braided, gravel bed rivers using digital photogrammetry and image analysis." Int. J. Remote Sens., 24(4), 795-816.

Williams, G. P. (1978). "The case of the shrinking channels-The North Platte and Platte Rivers in Nebraska." U.S. Geological Survey Circular No. 781, Washington, D.C.

Winterbottom, S. J., and Gilvear, D. J. (1997). "Quantification of channel bed morphology in gravel-bed rivers using airborne multispectral imagery and aerial photography." Regul. Rivers: Res. Manage., 13, 489-499.

Wright, C. W., and Brock, J. C. (2002). "EAARL: A LIDAR for mapping coral reefs and other coastal environments." 7th Int. Conf. on Remote Sensing for Marine and Coastal Environments, National Oceanic and Atmospheric Administration, Miami.

Wright, C. W., Hoge, F. E., Swift, R. N., Yungle, J. K., and Schirtzinger, C. R. (2001). "Next-generation NASA airborne oceanographic Lidar system.” Appl. Opt., 40(3), 336-342. 